\title{
Understanding how attitudes towards autonomous vehicles can shape the design of cities
}

Dale Harrow PhD, MA, BA

Professor and Dean of School of Design and Acting Head of Programme, Vehicle Design, School of Design, Royal College of Art, London, UK

Rama Gheerawo MA, D(IC), BEng, FRCA, FRSA

Director, The Helen Hamlyn Centre for Design and Reader in Inclusive

Design, The Helen Hamlyn Centre for Design, Royal College of Art,

London, UK
Dan Phillips FRSA, MSt Cantab, BEng ACGI

School of Design, Royal College of Art, London, UK

(corresponding author: dan.phillips@rca.ac.uk)

Gail Ramster MEng, MA

The Helen Hamlyn Centre for Design, Royal College of Art, London, UK (Orcid:0000-0001-8864-7105)

Understanding public attitudes towards autonomous vehicles is an important starting point when designing and engineering future cities, both to ensure acceptance and to deliver social benefits. The GATEway project is a consortium of industry and academic organisations that are establishing a test bed for driverless vehicle technology within public streets in Greenwich, London. Each partner is using public trials to explore the potential for autonomous technology within a city transport network. The Royal College of Art (RCA) is exploring how public attitudes can be used to enhance social benefit. This paper shares first findings from a series of workshops including people with additional needs, non-drivers, drivers, technology enthusiasts and professional stakeholders. The workshops delved into people's hopes and fears for driverless technologies and used co-design methods to explore how designers can respond when designing autonomous vehicles, the services they provide and the wider urban environment.

\section{Introduction}

The idea of a 'driverless' vehicle can seem unsettling, partly because it suggests a lesser amount of control.

'Autonomous' vehicles on the other hand, might engender a different reaction: as something that is made to be self-governing, that doesn't have to be operated by humans because it can work things out for itself. The autonomous vehicle represents an advanced technology that does not need humans to function.

However, the autonomous vehicle is the next step in vehicle evolution (Begg, 2014; DfT, 2015; IET, 2014). The technology that it requires has existed in varying capacities for the last century - commercial aeroplanes, for example, are heavily automated, meaning they can take off, fly and land on their own. So what do people think of when autonomous technology is presented to them as an inevitability?

As a popular subject for Sci-fi, robotics has often been portrayed as something that can go terribly wrong: Skynet, a self-aware form of artificial intelligence from the Terminator franchise (Skynet, n.d.), is bent on destroying humankind; Isaac Asimov's short stories from the I, Robot series (1940-1950) contain some of the best-known examples in which humans struggle to control robots precisely because they are designed to be autonomous. Indeed, the idea of autonomous robotics presents some ethical and philosophical questions - as demonstrated by Asimov's character Cutie (QT1) who, building on Descartes' philosophical proposition, says: 'I myself, exist, because I think' (Reason, n.d.). Any public distrust and negative perception of autonomous vehicle technology could mean that its potential is not considered.

Existing research into public views of driverless vehicles have used quantitative methods (CMS, 2014; Deepblue, 2014), which often scratch the surface of public opinion. The aim has been to go deeper into people's underlying hopes and fears so that the researchers can share and respond to these feelings through tangible outputs that the general public and professional stakeholders can respond to in an open and non-directed debate.

\section{GATEway project}

The GATEway (2017) project aims to understand and overcome the technical, legal and societal challenges of implementing automated vehicles (SAE, 2017) in an urban environment, centred around public trials of autonomous vehicles in Greenwich. Project partners include the Transport Research Laboratory (the project leader), Royal Borough of Greenwich, Royal Sun Alliance, Shell, $\mathrm{O}_{2}$, Oxbotica, Westfield, Heathrow, University of Greenwich, Imperial College London, Commonplace and Gobotix (Figure 1).

The Helen Hamlyn Centre for Design (HHCD) (HHCD, n.d.) and the Vehicle Design programme at the Royal College of Art 


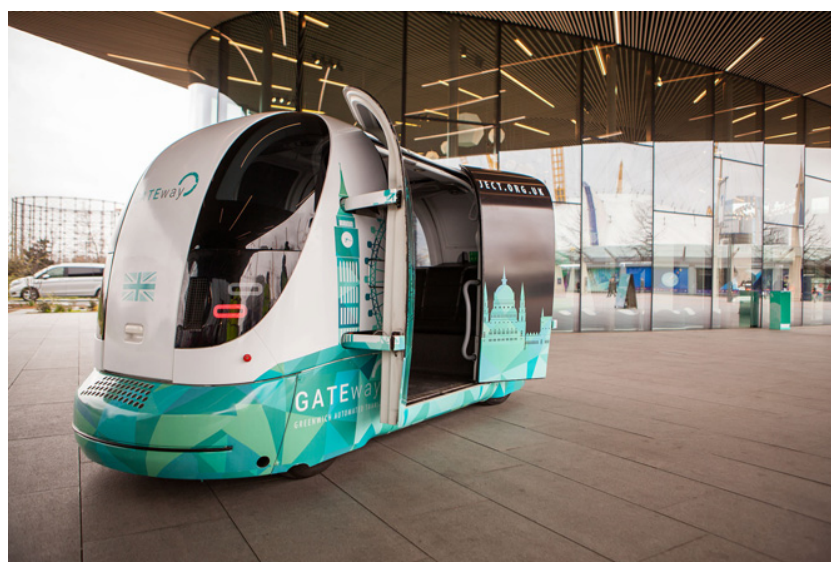

Figure 1. The GATEway driverless shuttle

(RCA, 1941) are exploring the public's attitude towards the new technology in an effort to understand how their preconceptions of autonomous vehicles might be taken into account in the design of future vehicles, services and infrastructure. It's about engaging the public in conversation about the technology from the beginning to understand the context for existing attitudes but also to explore the potentially boundless possibilities of what autonomous vehicles could bring to the city.

The team are approaching GATEway through two perspectives.

The first gathers information from co-creation workshops, which are an integral part of the HHCD's design methods (HHCD, n.d.). People with a variety of backgrounds (from experts in robotics to people with additional needs in terms of mobility) were invited to engage in discussions and creative activities, and to think about sets of questions and scenarios that allow the team to gain an insight into why some might be excited by or fearful of the new technology and what people would like autonomous vehicles to offer them. The workshop findings then inform design briefs for both the team and for RCA students from the MAVehicle Design course.

The second part to the project delivers these ideas for vehicles, services and even architectural spaces to the public through public exhibitions. Some may show more straightforward A to B car journeys; others however, are more explorative and conceptual: a hotel on wheels for transcontinental holidays, a road drone that absorbs noise pollution, or a shower vehicle for the journey home.

Working in tandem, it is hoped that the public workshops and exhibitions will not only generate more insights into how autonomous vehicles could positively impact on people's lives with real social value, but also influence the future development of this technology and design possibilities, with the new direction that autonomous technology brings.

\section{Methodology}

The objective of the workshops was to understand the following research questions

- What are people's perceptions and attitudes towards autonomous vehicles that will be important when designing for acceptance and adoption?

- How might the design of autonomous vehicles influence people's perceptions and attitudes to make acceptance and adoption more likely?

With the support of The Transport Research Laboratory (TRL), over 100 people were recruited to attend eight late-afternoon workshops in Greenwich, London. In order to ensure a range of views, people were selected into the following categories: drivers, non-drivers, enthusiasts, professional stakeholders and those with additional needs. Five of the workshops were focused on these specific groups and three were open to people from any category.

The participant groups included 33 women and 74 men, five people between 18-24, 39 between 25-34, 29 between 35-44, 14 between 45-54, ten between 55-64 and seven over 65 (Figure 2). Of these, 13 had additional needs including visual impairment, deafness and wheelchair use. Six classified themselves as cyclists, six as pedestrians, nine mainly used buses, 19 regularly drove cars, 21 used a mix of various modes apart from cars and 38 mainly travelled by trains/tubes.

Before the workshop, guests were invited to fill in an online form describing what they like and dislike about travelling around London as well as their impressions of sending or receiving parcels and post; thus covering much of the traffic that fills the streets of the city centres. This gave the researchers a baseline understanding of the issues that people might consider important about mobility in the city.

On arrival, guests were asked to fill in a couple of simple questionnaires about themselves and their knowledge and attitudes to driverless vehicles. They were also asked to decide whether driverless vehicles were good or bad for the environment, safer or more dangerous than existing vehicles, cost effective or expensive, and whether they would be mainly privately owned or shared. They also had an opportunity to describe their view of future technology in the city and what they would like to spend their time doing when travelling in a driverless car.

To kick-start the session, a short clip from Minority report was shared, with researchers explaining that Hollywood technologists have already imagined a driverless future and this is an opportunity for the public to shape the future that they want rather than 


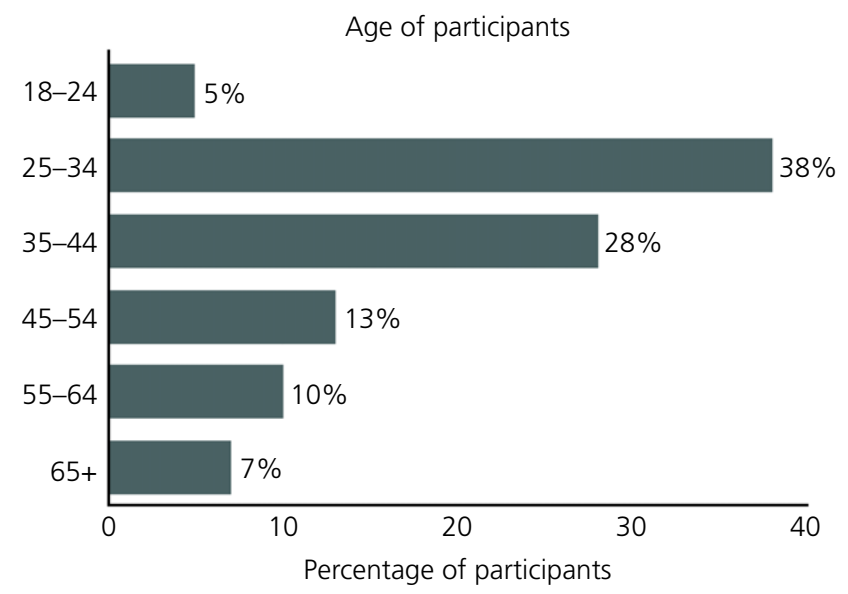

Figure 2. Age distribution of participants

leaving it to futurologists. Participants were then divided across four tables so that smaller groups could build a rapport and engage in deeper conversations with the support of a facilitator from the Helen Hamlyn Centre for Design.

The first exercise asked participants to write down all their hopes around driverless vehicles. To help them, the researchers highlighted the key areas that prior research has already established, including safety, cost, ownership, environment and other social and cultural issues (IET, 2014). Once participants had written down their personal thoughts, they worked together to share their thoughts and explain ideas in more depth. The facilitators recorded the conversations for future transcription.

This exercise was then repeated, but with participants thinking about their fears and concerns for the future. The researchers highlighted one potential dystopian future using a video clip from WALL_E but left the participants to decide which elements of this were meaningful to them (Figure 3). After a break, the groups were divided into pairs and asked to develop a scenario for a current journey around London. They described what sort of journey they were taking, who was travelling, what they were carrying and the time and conditions on the journey.

They chose a start and a destination and then mapped out all the challenges that they might face on the journey. These included issues around getting to the vehicle, getting in and out, transporting baggage, activities and issues during the journey, traffic jams, changing modes of transport, refuelling, parking and paying for the trip (Figure 4). They were asked to imagine a driverless future and show how vehicles, services and city infrastructure might adapt to solve the problems that they had highlighted as well as creating a more delightful experience for all the passengers (Figure 5).

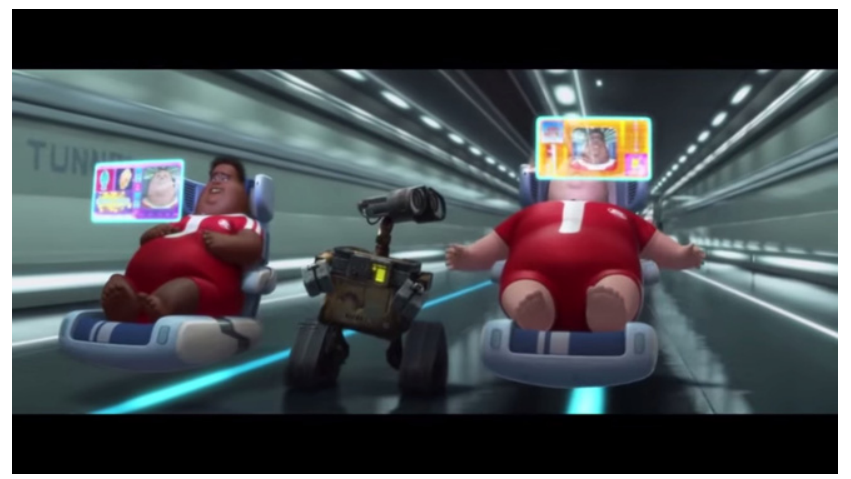

Figure 3. Still from Wall_E showing a possible dystopian future

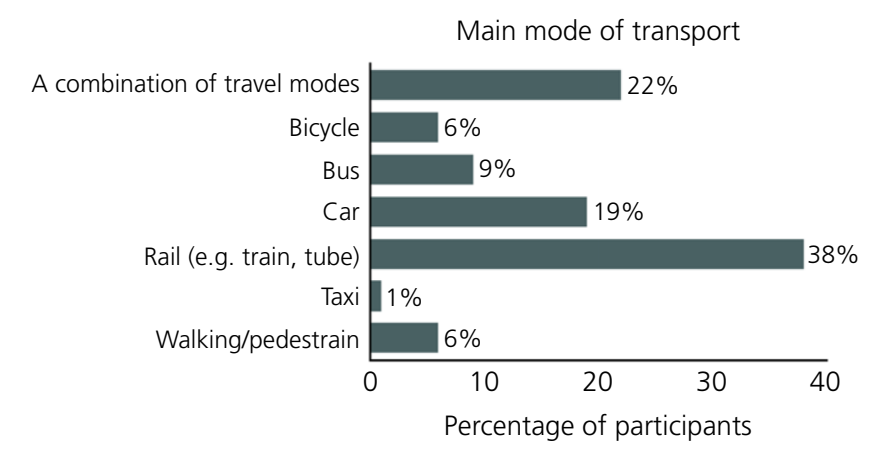

Figure 4. Main mode of transport for participants

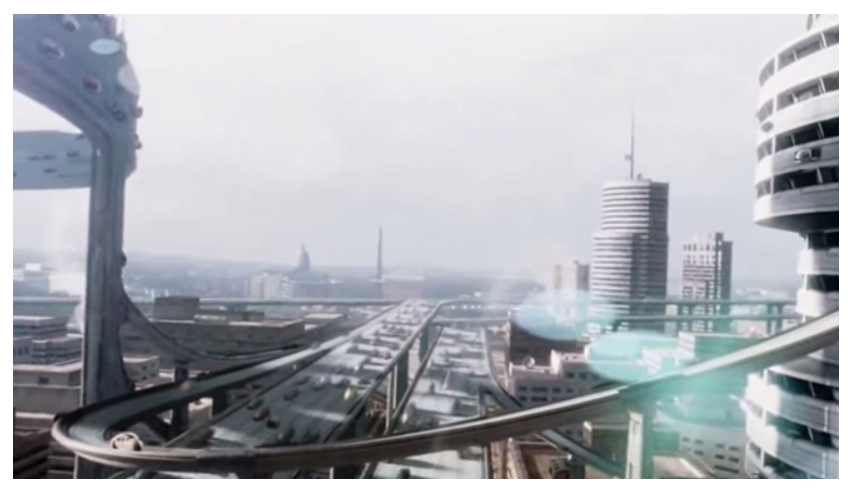

Figure 5. Still from Minority report imagining a driverless future

The teams were then asked to create a checklist highlighting all the elements that might help them to achieve this dream experience. Finally they were given Lego, Plasticine, paper and pens and asked to build a model of the driverless vehicle of their dreams and then explain the features that made this achievable. Some teams produced three-dimensional models; 
others made notes and drawings and one or two focused on future infrastructure and smart city streets.

The final task asked guests for feedback on the event and ways that the experience might be improved. The majority of people enjoyed the session (scoring an average of 4.5 out of 5) and felt that they had been able to contribute and learn from others in a creative and open space. They were also asked if they had changed their views towards driverless vehicles.

During the workshops all conversations were recorded, highlights of discussions and vox pops with individual participants were filmed, and photos were taken of the teams and activities. An illustrator also created a real time record of the event. They captured some of the conversations, turned them into pictures for discussion and also created a record of the whole workshop for the researchers to reflect on.

After the workshop, the audio recordings were transcribed and qualitative analysis software (Atlas.ti) was used to organise information, highlight interesting quotes and identify concepts that might inform potential design opportunities and challenges. While not being over-prescriptive, some of the areas that the researchers were interested in identifying included the themes that were used in the hopes and fears activity (environment, safety, cost, ownership and social/cultural issues), people and their feelings, journeys and services, as well as features and qualities of vehicles or infrastructure that were discussed (Figure 6).

\section{Results}

Further engagements are planned, including meeting participants during the trial of the shuttle vehicle in Greenwich and as part of a public exhibition that the research team is developing, so the results that are being shared here are still

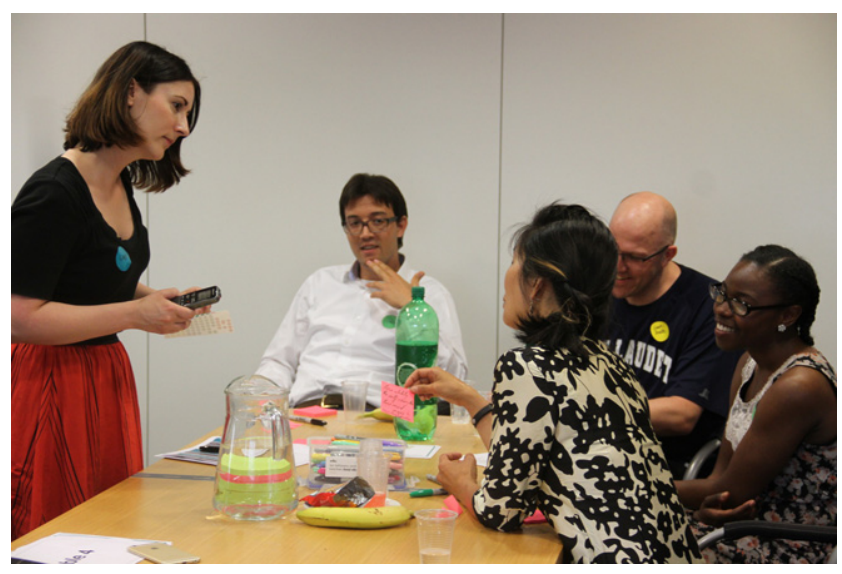

Figure 6. Discussing participants' hopes and fears during the workshops

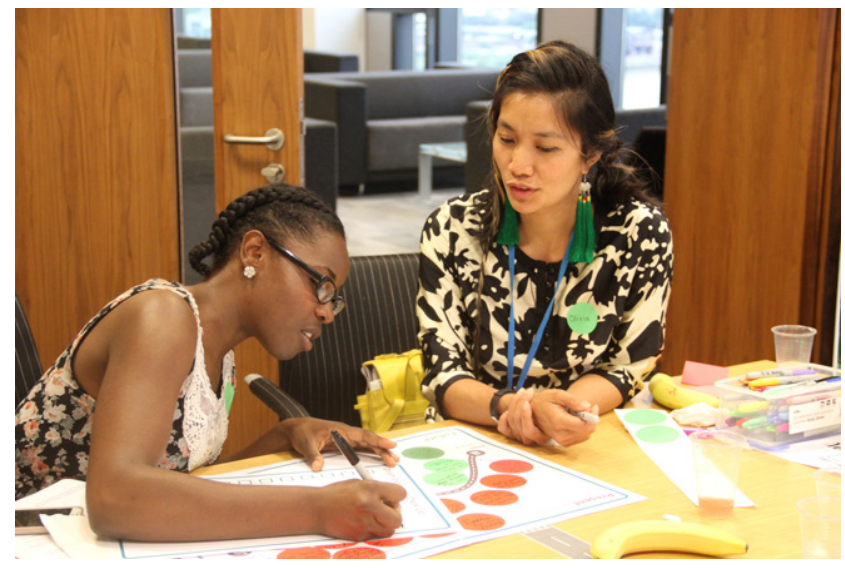

Figure 7. Participants developing their dream driverless checklist during the workshops

preliminary (Figure 7). However, of course, there were clear advantages in understanding people's attitudes to autonomous vehicles before they experience them at first hand.

\subsection{Likes and dislikes about current journeys and goods delivery}

People enjoy the density, flexibility and convenience of public transport in London, the opportunity to walk or cycle when conditions were good and the freedom and perceived improvements in choice, comfort and speed that came with personal vehicles. Conversely they expressed concerns around issues like traffic jams and congestion, overcrowding and delays, noise, pollution and unpleasant environments.

When they thought about packages and parcels, they felt that things were generally improving with faster deliveries, greater certainty around timing as well as innovations like shop-based lockers, pickups and drop off, and the sheer delight and pleasure of receiving a handwritten postcard in an era that is becoming more and more digitised. Some found no pleasure in posting and parcels, with many expressing dismay around missed deliveries, damaged or lost parcels, increasing costs and the difficulty of moving things around town if they were overloaded or had additional needs.

\subsection{Knowledge and attitudes}

Most of the participants said they had a limited or average knowledge of driverless vehicles with only $6 \%$ saying that they were experts in the field.

When asked how they would describe autonomous vehicles, $67 \%$ used the terms driverless or self-driving with only $32 \%$ choosing autonomous or robotic. 


\section{Offprint provided courtesy of www.icevirtuallibrary.com Author copy for personal use, not for distribution}

At the start of the workshops $75 \%$ of participants were positive about the technology, 24\% were unsure and 1\% were concerned, but by the end of the activities the number of positives had increased to $87 \%$ with only $13 \%$ still unsure. While changing attitudes was not the aim of the workshop, it's important to note that active but neutral engagement with the general public is an important way of allowing people to change their attitudes, at least in the short term.

More detailed attitudes to driverless vehicles were also generally 'positive'. In all, $89 \%$ felt they would be safer than current vehicles, $73 \%$ that they would be shared rather than owned, $75 \%$ that they would be cost effective rather than expensive and nearly everyone thought they would be better for the environment. Hidden within these attitudes are fundamental hopes for a safer, more inclusive, cleaner and calmer city where streets and places are designed for people rather than for vehicles and the supporting infrastructure that currently dominates their design.
Many participants thought that driverless vehicles were the future of transport in the city, and the network of vehicles and sensors would create an exciting, efficient and potentially revolutionary transformation in how cities develop both spatially and economically.

As for the activities that they imagined doing in them, they mainly reflected current behaviours on public transport such as reading, watching media, chatting with friends or having a nap. Some expressed the desire to watch the world go by, explore new places or chat with fellow passengers. Designing with these activities in mind rather than simply designing vehicles as a transport utility might open up opportunities for new services, new social patterns and different types of economic activity.

\subsection{Hopes and fears}

Over the eight workshops, people shared over 700 'hopes' and a similar number of 'fears' (Figure 8).

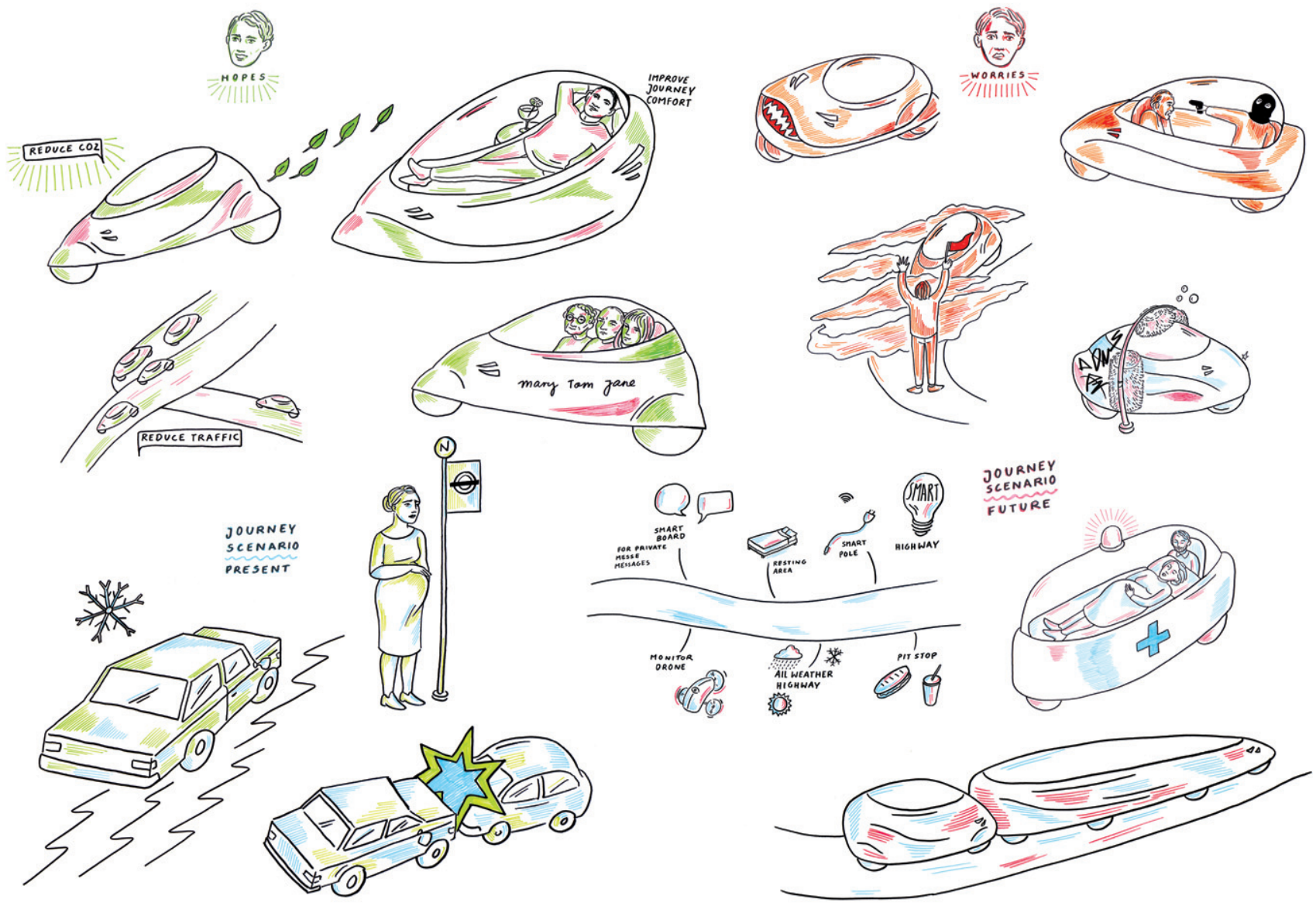

Figure 8. Illustrations of people's hopes and fears created during the workshops 
Major hopes centred on the freeing up of time, as cities become less congested and the time during journeys becomes more useful and valuable. They felt that driverless vehicles would create healthier and safer city environments leading to less stress, less pollution-related illness and more social and convivial streets and journeys (Figures 9-12).

Interesting quotes included:

'I no longer need to be the driver when my mates go to the pub'

'I love cycling around London when there are few cars. The cars and the trucks, they ruin it for everyone.'

'More space, instead of cars filling up the parking spaces.'

'I, personally, would ensure that everyone just use public transport, permanently. That's my view.'

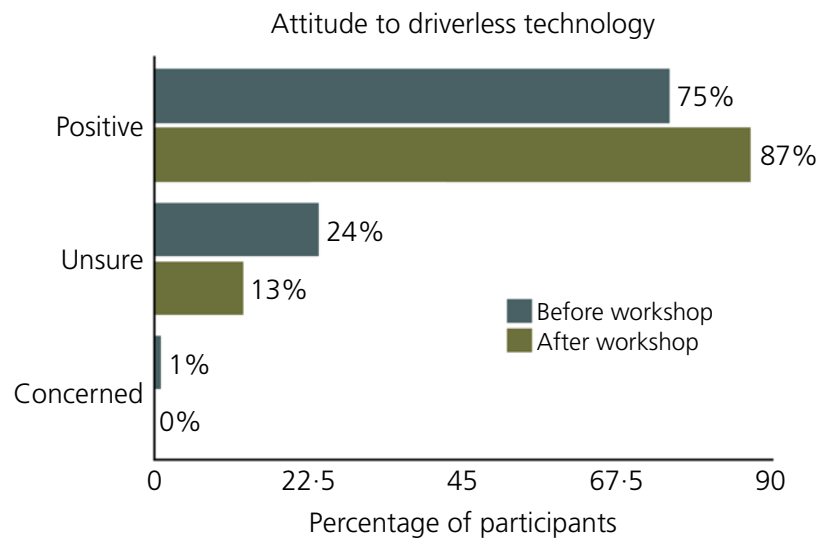

Figure 9. Participants' overall attitude towards driverless vehicles before and after the workshops

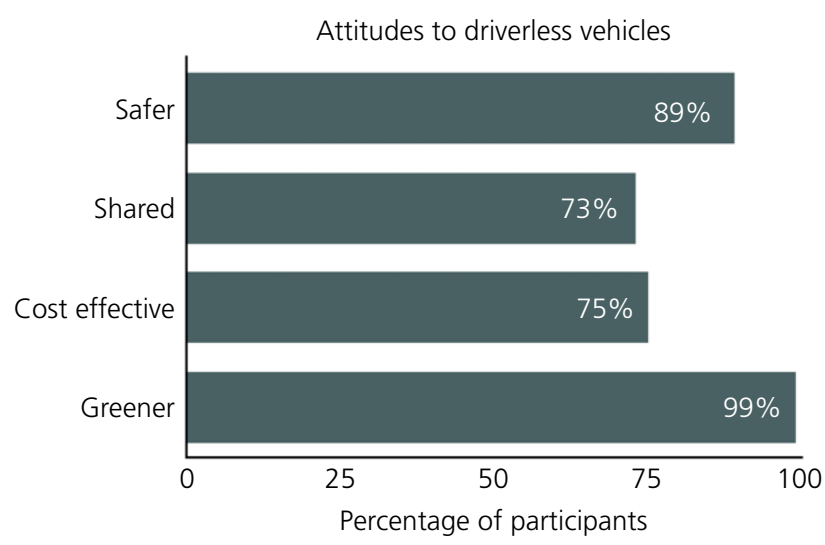

Figure 10. Participants' detailed attitudes towards driverless vehicles before the workshop

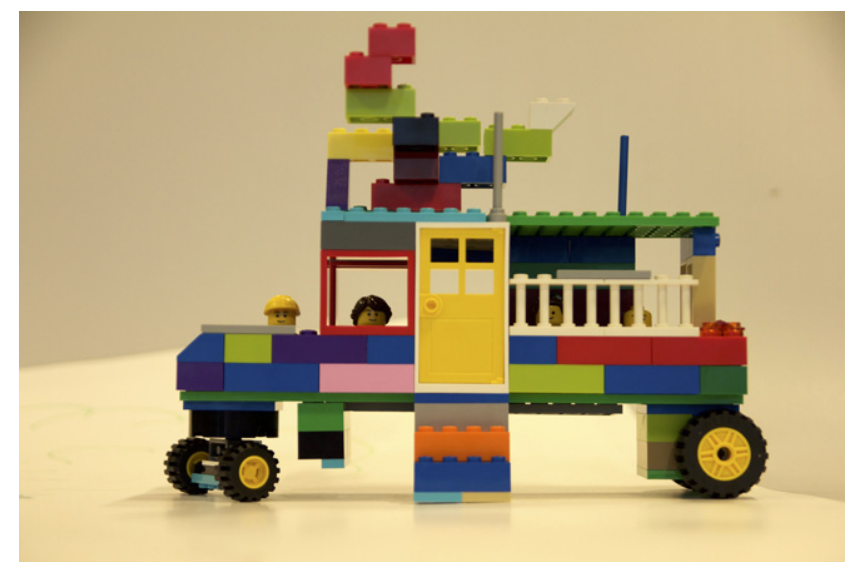

Figure 11. Example of a dream driverless vehicle developed during the workshop

\subsubsection{Hopes}

Safety:

- Safe streets, even for hedgehogs

- No more drunk, rude or dangerous drivers

Ownership:

A spare room people can take on their travels

Sharing:

- Travel on demand - less need for centralised transport infrastructure

Environment:

Redesign streets for people

- Quiet, clean and pollution free

- No need to park

- Smaller vehicles as you don't need to pay for the driver

- More self-diagnosis so that vehicles can take themselves for a service before becoming unsafe, noisy and so on

Social and cultural issues

- More comfortable commutes and journeys

- Driverless vehicles for all - accessible and affordable transportation

- More time to do fun or useful things on journeys

- Advertise local businesses and events

- Noise cancellation built into driverless vehicles

People's concerns included the impact on employment as 'robots' take over existing jobs and economic activities, fears 


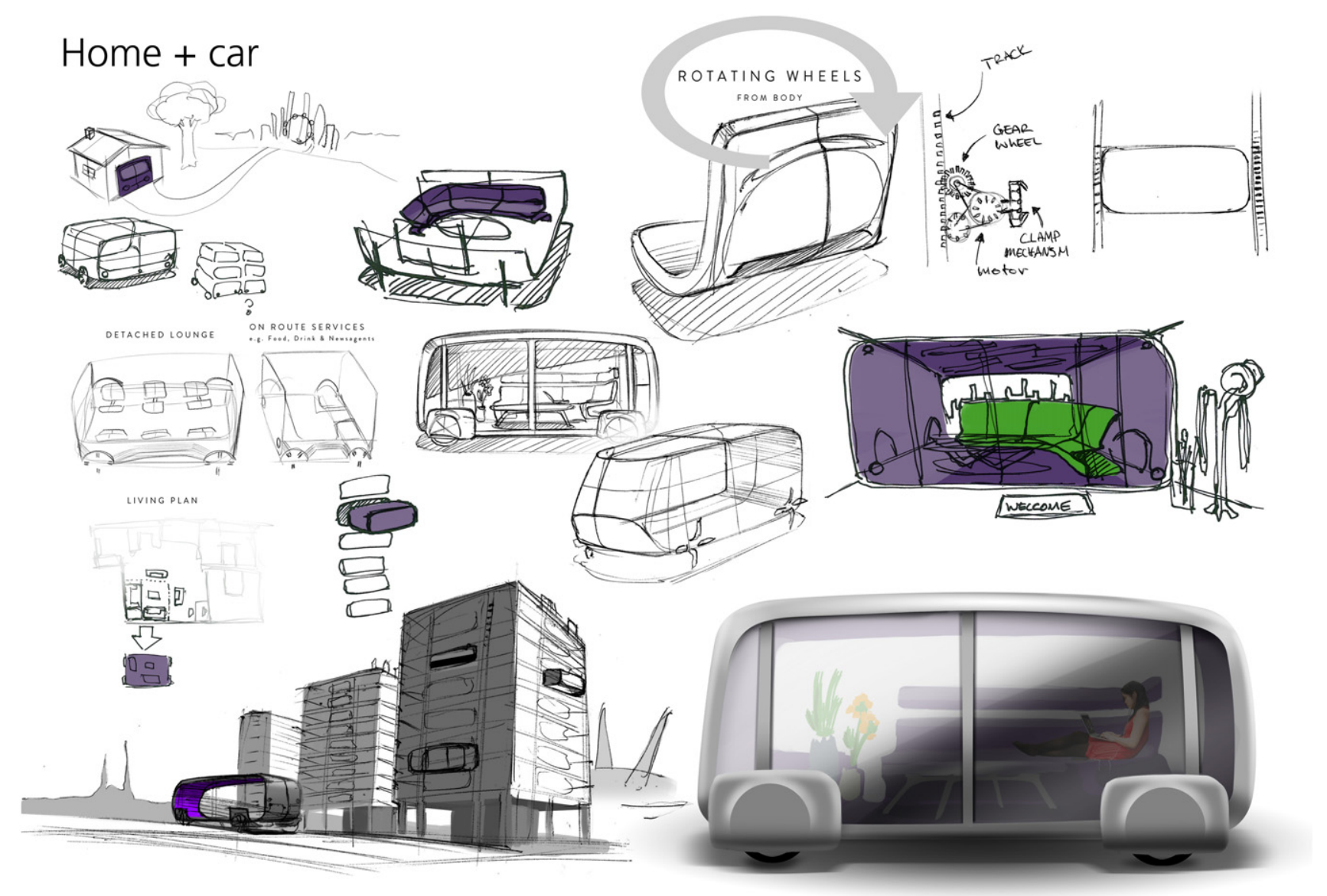

Figure 12. Example of a designer's response to a dream driverless vehicle developed after the workshop

around data privacy, the ethical judgement of autonomous but supposedly intelligent vehicles, the loss of independence that might come when driverless vehicles control how people use the street, the challenges of cybercrime and the impact that on-demand vehicles will have on people's health as they find it easier and cheaper to get door-to-door transport rather than walking or cycling around town.

\subsubsection{Fears}

Safety:

- Greater use of quieter vehicles makes the city less safe for partially sighted or distracted pedestrians

- Transition to single surface roadways will make it even harder for people with additional needs to navigate and cross streets

- Can't make eye contact with an autonomous vehicle

- Ethical dilemmas around accidents

\section{Ownership:}

- Less opportunity to personalise the vehicles that people use

Sharing:

- Increased potential for antisocial behaviour when there are no drivers.

- Shared, dirty and 'not cared for' vehicles

Environment:

- Cities will grow as people accept longer 'useful' journeys

- Driverless vehicles will compete with public transport making streets even busier than before

- An invisible network that makes the city less legible

- Dead high streets as more and more is delivered by just-in-time vehicles 


\section{Social and cultural issues}

- Big business will control the transport network based on profit and track us constantly

- Cities will become more isolated, robotic and inhuman

- People will become lazier as door-to-door journeys become easier and cheaper

- Always connected - work, work, work

- Job losses and loss of skills

- Vehicles start to tout for business

- Vehicles create a lonely isolated and more disconnected environment

- Low-cost door-to-door vehicles encourage laziness

- Inhumane and robotic systems that are pre-programmed and dull

Interesting quotes included:

'Privacy is a thing of the past.'

'AI is coming into law, into accounting, and into HR and into all sorts of areas, so lots of people are going to be without jobs.'

'Could meet (even more) annoying new people in your community'

'I can't make eye contact or receive eye contact information from (robots)... I can't give them a nod and a wink'

'Software always has bugs. It's always scary, but I'm sure they are going to figure it out. It's a concern. It's their safety I guess.'

'I like my own car, set up for me, my music, my kids seat in the back'

'How do you prevent big brother from tracking your journey?'

Each of these hopes and fears can translate into opportunities for specific design studies that allow us to challenge purely functional requirements and create better social experiences and outcomes.

\subsection{Current challenges and future opportunities}

Participants identified a wide range of challenges on their hypothetical journeys around London. These included obvious issues including congestion, bad weather, problems with parking and accidents, but also personal and interpersonal issues such as lack of space, arguments between passengers, the need for step-free access and the common problem of needing to find a toilet en route.

Therefore, how did driverless vehicles and systems help to solve these challenges? Journey planning issues were solved by on-demand services where vehicles could be ordered to meet specific needs; intelligent highway and maintenance systems helped to reduce problems associated with vehicle breakdowns or road works; and the interiors of vehicles had features that helped to deal with the social challenges of travelling together. For families, vehicles supported more playful experiences for children, less stress for the parents and even hygiene features like a mobile toilet. For cyclists, intelligent systems delivered on-demand bike repairs while public transport allowed people to transport a bike on a shared bus if the weather took a turn for the worse. People with additional needs could travel with their friends or family rather than using a mobility scooter while shoppers could send their purchases home in a separate 'goods' pod' while they met up with friends or went for a meal.

\subsection{Experience features and future vehicles}

These opportunities were converted into checklists and threedimensional models that represented the future driverless experience for the participants. Features ranged from the simple and mundane to the exotic and far-fetched. Many of the vehicles were delivered on-demand and set up with a range of features that were suited to the type of journey. The basic requirements included easy access by way of ramps or sliding doors; adequate space for everyone and everything including children, pets and luggage; personalisation of entertainment systems to suit individuals or groups; comfortable chairs and space that support different activities including work, play and individual contemplation. More radical ideas included beds; massage chairs; fridges to store on-demand food and waste disposal systems to deal with leftovers; exercise machines, toilets and showers to keep fit or freshen up on the go.

While people with additional needs were particularly concerned about the overall sensory environment, they were not alone in wanting a safer, pleasant and engaging environment. The soundscape should be attractive but audibly different so that guide dogs and blind people were aware of these potentially silent machines; air should smell pleasant, materials soft but easy to clean; windows should be fully adjustable to create entertainment spaces, to transport passengers into a different experience or to connect them more intelligently to the city that they are travelling through.

The vehicles were serviced by a range of just-in-time support services including separate goods vehicles, mobile food delivery systems, maintenance and refuelling systems that were connected to and controlled by intelligent assistants.

Many of these features show that people see driverless vehicles in a completely different light to existing transport services, more akin to mobile homes, workspaces and hotels than cars, buses and trains. 


\section{Conclusions}

This public engagement has shown a real appetite to reimagine road-based transport systems from the ground up, not simply to retrofit 'autonomy' to existing vehicles but to radically reimagine how people use transport for public benefit.

When thinking about adoption patterns it becomes clear that the innovators and early adopters in this space might well include people who are currently excluded from driving such as those with additional needs and the elderly. The early majority may be people who do not actually enjoy the current driving experience (which incidentally appears to be the majority of city dwellers) and would prefer to spend time with their families and friends or focusing on work than guiding a vehicle through busy streets. The driverless laggards by contrast may be 'motoring enthusiasts' who enjoy being behind the wheel for a variety of reasons - whether because the vehicle is an extension of their personality or because the experience itself is enjoyable no matter the external conditions. This is a reversal of familiar patterns of technology adoption where early adopters are often young and relatively affluent (Schelly, 2014).

Design challenges come from people's fears as well as from the potential excesses of on-demand mobility.

How do driverless vehicle services connect with social structures to avoid an increase in isolated and inhuman city environments?

How do driverless vehicles and services create new opportunities for meaningful work and economic activity in the city? Could they form part of employability services by integrating mobility with accessibility in the context of local economic systems? Could they make it easier for people to collaborate or take part in aspects of the developing 'shared' and 'circular' economy?

How are streets and external environments redesigned to support active mobility while also making best use of driverless vehicle features to reduce congestion and improve the city's environmental qualities? Can driverless vehicles support mixed-mode active travel by integrating with cycle systems or create mixed-mode journeys that provide options for walking through parks and other green infrastructure?

How might driverless vehicles and their interiors be designed so that they are attractive, easy to maintain and discourage vandalism or other anti-social behaviour? How might design create calm and clean environments that reduce stress and help travellers to relax when out and about?

How are driverless vehicle services created so that they use automation and intelligent software in a way that is ethical, humane and natural? How does the materiality of driverless vehicles affect people's relationship with them and the services that they provide?

How are driverless services developed so that they integrate with existing forms of public transport and avoid the potential increase in smaller vehicle usage and the consequent impact on road infrastructure?

How are driverless vehicle services made 'legible' within a city in the context of digitisation and the dematerialisation of infrastructure?

How are driverless delivery services designed so that robotic drones and mini pavement bots don't overwhelm the skies and streets of the city?

Design opportunities come from the hopes that people expressed as they reimagined city mobility for both practical and delightful reasons.

How are shared vehicle interiors designed to support more comfortable, social or useful commutes? What do family friendly interiors look like? What will vehicles look like if they support existing and new forms of work?

What do future streets and 'villages' look like when shared driverless vehicles are the norm? What happens to existing parking spaces? Should they be used to increase green lungs or be redeveloped to increase the density of buildings?

What are the public services that driverless vehicles might perform and should these vehicles be specialist or general purpose? Could they help to keep the streets clean and safe as well as provide additional support for families with kids or older folk who need help with their shopping?

What do the centralised or distributed services that support driverless vehicle systems look like? How and where will vehicles park, refuel themselves, be cleaned or be maintained?

What do service vehicles look like when they no longer have to 'pay for the driver'? Will they become smaller and what will these small service vehicles look like? Mini delivery vehicles, rubbish collectors, local shuttles and building material bots?

How are additional needs integrated into general service driverless vehicles rather than creating bespoke segregated services that isolate rather than celebrate differences?

\section{Next steps}

These conclusions are not exhaustive and the researchers will continue to develop design principles and road maps for 


\section{Offprint provided courtesy of www.icevirtuallibrary.com Author copy for personal use, not for distribution}

potential rollout of vehicles, services and infrastructure based on further engagement with the wider public.

Next steps include follow-on workshops, design-led responses with teams of designers from the RCA, and exhibitions that share these explorations with the general public at the London Transport Museum and on the Greenwich Peninsula.

\section{Relevance to the engineering community}

People are keen to see a transformation in the city environment, the experience and impact of moving around the city and the opportunities to create greater value and more inclusive services than are currently achieved.

Driverless vehicles can help to catalyse this change but the public also recognise, and are concerned by, the potential dehumanisation of the city, the centralisation of control and ownership, and the unforeseen consequences of this radical transformation.

The engineering profession, in all its specialities, is intimately involved with these issues at every level; from the design of the software that manages vehicles and infrastructure, to the design of the vehicles and the reshaping of the streets and interchanges that support city life. The hope is that this paper has shown the value of a people-centred approach to technology-led research. The authors are keen to engage with engineers and other professionals to ensure that these insights are fully integrated into their own skills and methods.

\section{Acknowledgements}

The authors would like to acknowledge the support of the Department for Transport (DfT) and the Department for Business, Innovation \& Skills (BIS) through Innovate UK and the Centre for Connected and Autonomous Vehicles (CCAV), together with additional support from the commercial organisations within the GATEway consortium.

\section{REFERENCES}

Begg D (2014) A 2050 Vision for London: What are the Implications of Driverless Transport'. Transport Times, London, UK. See http://www.transporttimes.co.uk/Admin/uploads/64165-TransportTimes_A-2050-Vision-for-London_AW-WEB-READY.pdf (accessed 09/08/2016).

CMS (2014) Automated Vehicles: What the Public Thinks - Sciencewise. Sciencewise Expert Resource Centre, London, UK. See http://www.sciencewise-erc.org.uk/cms/assets/Uploads/Automatedvehicles-what-the-public-thinksNov-15.pdf (accessed 07/12/2017).

Deepblue (2014) A Survey of Public Opinion About Autonomous and Self-Driving Vehicle. The University of Michigan Transportation Research Institute, Ann Arbor, Michigan, USA. See https://deepblue.lib.umich.edu/handle/2027.42/108384 (accessed 07/12/2017).
DfT (Department for Transport) (2015) The Pathway to Driverless Cars: A Detailed Review of Regulations for Automated Vehicle Technologies. Department for Transport, London, UK. GATEway (2017) GATEway Project. TRL, Wokingham, Berks, UK. See https://www.gateway-project.org.uk/ (accessed 07/12/2017).

$\mathrm{G}$ F, Bichard JB, Langdon P et al. (2015) A vehicle for design ures: exploring the experience of driving in the present to inform an inclusive future. In Design Anthropological Futures, Conference of The Research Network for Design Anthropology, Copenhagen, Denmark.

HHCD (Helen Hamlyn Centre for Design) (n.d.) The Helen Hamlyn Centre for Design. HHC. https://www.rca.ac.uk/researchinnovation/helen-hamlyn-centre/ (accessed 07/12/2017).

IET (Institution of Engineering and Technology) (2014) Autonomous Vehicles: A Thought Leadership Review of How the UK Can Achieve a Fully Autonomous Future. Institution of Engineering and Technology, London, UK.

Ja $\bigcirc$ lausner D (2014) Face-to-Face with Online, Hybrid Public 2 Lngagement. Commonplace (blog). See http://commonplace. is/thoughts/2014/10/21/face-face-online-hybrid-public-engagement/ cangessed 09/08/2016).

RC $\bigcirc$ al College of Art) (1941) Vehicle Design Programme|Royal College of Art. RCA. See https://www.rca.ac.uk/schools/schoolof-design/vehicle-design/ (accessed 07/12/2017).

Reason (1941) Reason (Short Story) - Wikipedia. Street \& Smith, New York, New York, USA. See https://en.wikipedia. org/wiki/Reason_\%28short_story\%29 (accessed 07/12/2017).

SAE (Society of Automotive Engineering) (2017) In This Context, Automated Vehicles Are Those That Can be Driven without Human Intervention - Levels 4 and 5 as Classified by the Society of Automotive Engineering. SAE, Warrendale, PA, USA. See https://www.sae.org/misc/pdfs/automated_driving.pdf (accessed 01/11/2017).

Schelly C (2014) Residential solar electricity adoption: what motivates, and what matters? A case study of early adopters. Energy Research Social Science 2(2): 183-191.

$\mathrm{s} \supseteq$ (n.d.) Skynet (Terminator) - Wikipedia. Skynet. See https://en.wikipedia.org/wiki/Skynet_\%28Terminator\%29 (accessed 07/12/2017).

\section{How can you contribute?}

To discuss this paper, please email up to 500 words to the editor at journals@ice.org.uk. Your contribution will be forwarded to the author(s) for a reply and, if considered appropriate by the editorial board, it will be published as discussion in a future issue of the journal.

Proceedings journals rely entirely on contributions from the civil engineering profession (and allied disciplines). Information about how to submit your paper online is available at www.icevirtuallibrary.com/page/authors, where you will also find detailed author guidelines. 